УДК 551.464(262.54):519.233.5

\title{
ПОЛЕ СОДЕРЖАНИЯ ОКРАШІЕННОГО РАСТВОРЁННОГО ОРГАНИЧЕСКОГО ВЕЩЕСТВА И ЕГО СВЯЗЬ С СОЛЁНОСТЬЮ В РАСПРЕСНЁННЫХ ПРИБРЕЖНЫХ ВОДАХ АЗОВСКОГО МОРЯ*
}

Ломакин П. Д., Завьялов Д. Д.

ФГБУН ФИЦ «Морской гидрофизический институт РАН», г. Севастополь, Российская Федерация, e-mail:p_lomakin@mail.ru

На основе материалов серии экспедиций, проведённых Морским гидрофизическим институтом (г. Севастополь) и Южным научно-исследовательским институтом морского рыбного хозяйства и океанографии (г. Керчь) в 2002-2015 гг., получено уравнение регрессии, свидетельствующее о наличии тесной обратной корреляционной связи между солёностью и концентрацией окрашенного растворённого органического вещества в прибрежных водах северной части Азовского моря. При помощи этого уравнения по схемам средней месячной солёности рассчитаны сезонные поля содержания исследуемого вещества для всей прибрежной акватории моря, которая испытывает влияние речного стока. Показано, что у подверженных распреснению северного и восточного берегов моря поле исследуемой величины содержит существенную терригенную составляющую, которая значительно трансформируется на стоковых фронтах впадающих в Азовское море рек. Мористее фронтов в центральной, западной и южной областях Азовского моря поле окрашенного растворённого органического вещества однородно.

Ключевые слова: окрашенное растворённое органическое вещество, солёность, загрязнение, Азовское море.

\section{Введение}

С 40-х годов прошлого столетия по настоящее время в Азово-Черноморском бассейне активно изучаются репрезентативные показатели содержания растворённого органического вещества (РОВ), РОУ - растворённый органический углерод и ВОУ - взвешенный органический углерод. Результаты этих исследований, которые в основном касаются биохимических свойств указанных величин, обобщены в монографии [Агатова, Лапина, Торгунова, 2018] и атласе [Climatic atlas..., 2006].

Известна попытка океанографического исследования поля концентрации РОУ, предпринятая сотрудниками ВНИРО. Построенные схемы распределения концентрации РОУ в Чёрном море, по мнению их авторов, оказались приближёнными. Вместе с тем они позволили получить первые представления о структуре поля содержания РОУ в прибрежной области и в кислородной зоне глубоководной части Чёрного моря [Агатова, Лапина, Торгунова, 2018].

В настоящей статье представлен результат океанологического исследования поля оптического показателя РОВ - его флюоресцирующей составляющей, определяемой оптическим методом. В англоязычной литературе данная величина (colored dissolved organic matter) имеет стандартную аббревиатуру fDOM [Shanmugam et al., 2016], которая использована в тексте статьи. Цель настоящей работы - на основе данных серии экспедиций получить уравнение регрессии, связывающее солёность с концентрацией fDOM в прибрежных водах северной части Азовского моря; при помощи этого уравнения по обеспеченным массивам солёности рассчитать и проанализировать сезонные поля содержания исследуемого вещества для всей прибрежной акватории моря, испытывающей влияние речного стока; выявить закономерности сезонных вариаций в поле fDOM.

\footnotetext{
*Работа выполнена в рамках государственного задания по теме № 0827-2019-0004 «Комплексные междисциплинарные исследования океанологических процессов, определяющих функционирование и эволюцию экосистем прибрежных зон Чёрного и Азовского морей». Исследование проведено при финансовой поддержке РФФИ и г. Севастополя в рамках научного проекта № 18-45-920068.
} 


\section{Материалы и методы}

Рассматриваемый в настоящей статье регион - прибрежные распреснённые материковым стоком воды Азовского моря, солёность которых менее 10 ЕПС. Это Таганрогский залив и смежные с ним акватории вдоль северного и восточного берегов моря (рис. 1).

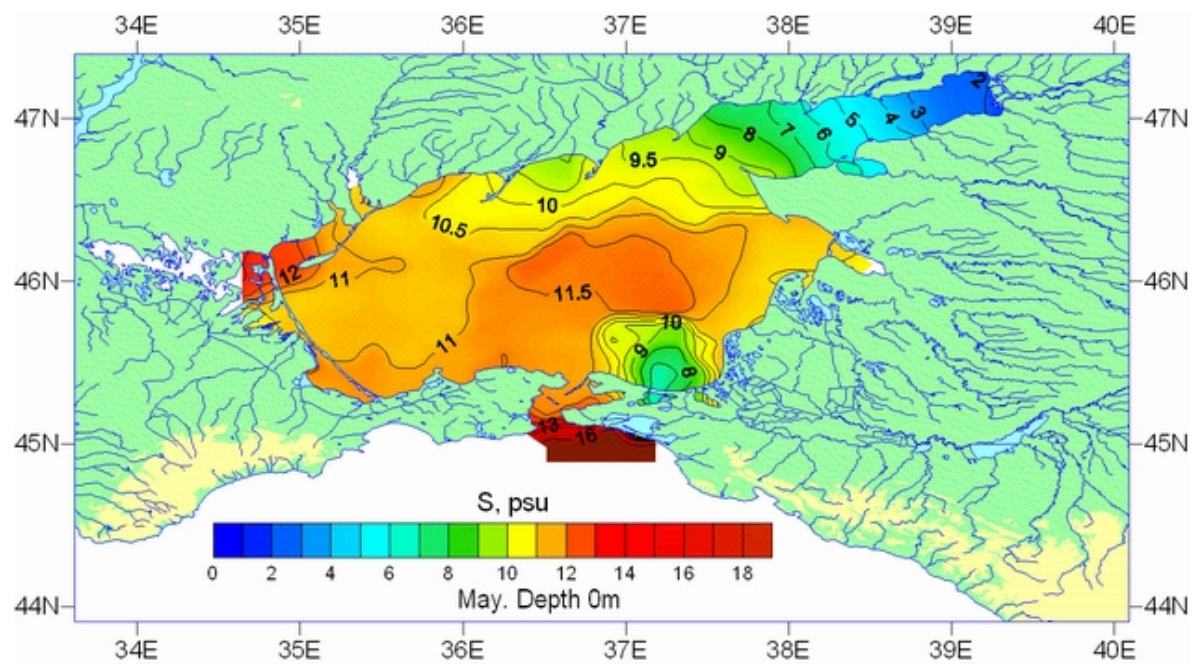

Рис. 1. Распределение средней месячной солёности,

ЕПС на поверхности Азовского моря в мае [Climatic atlas..., 2006]

В данной прибрежной распреснённой области в 2002-2015 гг., в рамках программ по изучению заморных явлений и загрязнения вод, как в тёплое, так и в холодное время года велись экспедиционные исследования МГИ и ЮгНИРО. Они представляли собой отдельные разрезы и съёмки участков акватории у пролива Тонкого, в Утлюкском лимане, в Бердянском заливе, вдоль мористого берега Бердянской косы, в районе Мариуполя, в устье реки Дон (табл. 1). У восточного берега Азовского моря необходимых наблюдений нет.

\section{Таблица 1}

Данные экспедиционных исследований с синхронной фиксацией солёност
и содержания fDОМ в северо-восточной части Азовского моря
\begin{tabular}{|l|c|c|c|}
\hline \multicolumn{1}{|c|}{ Район } & Дата & $\begin{array}{c}\text { Количество } \\
\text { ст. }\end{array}$ & S, ЕПС \\
\hline Пролив Тонкий & май 2004 & 8 & $9,8-10,0$ \\
\hline Утлюкский залив & август 2008 & 9 & $2,2-8,1$ \\
\hline Бердянский залив & сентябрь 2002 & 6 & $1,6-6,0$ \\
\hline Бердянская коса & декабрь 2007 & 27 & $6,4-10,0$ \\
\hline Мариуполь & июнь 2006 & 9 & $9,9-10,2$ \\
\hline Устье р. Дон & июнь 2015 & 4 & $0,8-1,0$ \\
\hline Всего & $2002-2015$ & 63 & $0,8-10,2$ \\
\hline
\end{tabular}

Используемый эмпирический материал - относительно небольшая по объёму выборка инструментальных наблюдений, всего 63 зондирования с синхронной фиксацией солёности и концентрации fDOM. 
Все данные получены при помощи портативного оптического зондирующего комплекса «Кондор» [Комплекс гидробиофизический..., 2021]. На каждом зондировании с шагом по глубине 0,1 м синхронно in-situ фиксировались солёность и концентрация fDOM. Размерность исследуемой величины fDOM представлена в единицах калибровки - сульфат хинина (QSU). Диапазон исследованных глубин - от 0,5-2,6 м в устье р. Дон до 9,2-10,2 м в открытых водах.

Возможность получить представление о структуре изучаемого поля на основе недостаточно ёмкой эмпирической выборки обеспечена существованием в морской среде тесной обратной корреляционной связи между солёностью и концентрацией РОУ, а также между солёностью и концентрацией fDOM. Статистические свойства подобных связей, характеризуемых высоким коэффициентом корреляции $(-0,68 \ldots-0,95)$ для прибрежных океанических и морских регионов, которые испытывают влияние материкового стока и расположены в различных климатических зонах, достаточно изучены и описаны в океанологической литературе [Пугач, Пипко, 2012; Kaiser et al., 2017; Kari et al., 2018; Sasaki et al., 2013; Chaichitehrani, 2012; Hopkins et al., 2013].

В анализируемом случае зависимость между солёностью и концентрацией fDOM была рассчитана методом парной корреляции. При помощи полученного уравнения регрессии средние месячные климатические поля солёности для прибрежных распреснённых акваторий Азовского моря из Атласа [Climatic atlas..., 2006], которые построены по хорошо обеспеченным выборкам фактических данных, были оцифрованы, а затем пересчитаны в поля концентрации fDOM. Пример одного из исходных полей солёности, использовавшихся для расчёта пространственного распределения fDOM на распреснённой акватории Азовского моря, приведён на рис. 1.

\section{Результаты и обсуждение}

В Таганрогском заливе и вдоль северного и восточного берегов Азовского моря расположена масштабная фронтальная халинная зона. В Таганрогском заливе и у северного берега моря она формируется стоком реки Дон, а также впадающими в северное побережье Азовского моря многочисленными реками с меньшей водностью: Берда, Кальмиус, Миус, Ея, Обиточная, Молочная и др. Акватория, примыкающая к восточному берегу моря, распреснена стоком второй по водности реки региона - Кубани, дельта которой занимает почти половину восточного берега. С моря эта масштабная распреснённая область ограничена стоковым халинным фронтом, мористая граница которого примерно совпадает с изохалиной $\mathrm{S}=10$ ЕПС [Гидрометеорологические условия..., 2009].

Расчёт коэффициента корреляции для верхнего слоя моря по исходной суммарной выборке выявил наличие слабой обратной статистической зависимости $(\mathrm{R}=-0,36)$ между исследуемыми величинами (рис. 2A).

На этом же рисунке видно, что исходная выборка включает обособленное облако точек $(\mathrm{N}=13)$ с повышенными значениями $\mathrm{fDOM}=128-151 \mathrm{QSU}$. Оно обведено и находится в области координатной плоскости с максимальной солёностью $S=9,8-10,5$ ЕПС.

Анализ мест расположения соответствующих станций показал, что они были выполнены на полигонах в окрестностях двух грунтовых свалок - в районах пролива Тонкого и Мариуполя. Первая свалка - результат дампинга грунта, изъятого в результате углубления пролива Тонкого, вторая - следствие дноуглубительных работ в порту Мариуполя.

Воды в районах свалок изъятого при углублении дна грунта насыщены растворённой органикой антропогенной природы, а сами зоны дампинга представляют собой серьёзные очаги экологической опасности [Stronkhorst et al., 2003; Simonini et al., 2005; Van der Wal et al., 2011; Donázar-Aramendía et al., 2018]. В анализируемом случае (рис. 2A) очевидно, что поле концентрации fDOM в исследуемой акватории Азовского моря содержало антропогенную составляющую, обусловленную влиянием грунтовых свалок. 


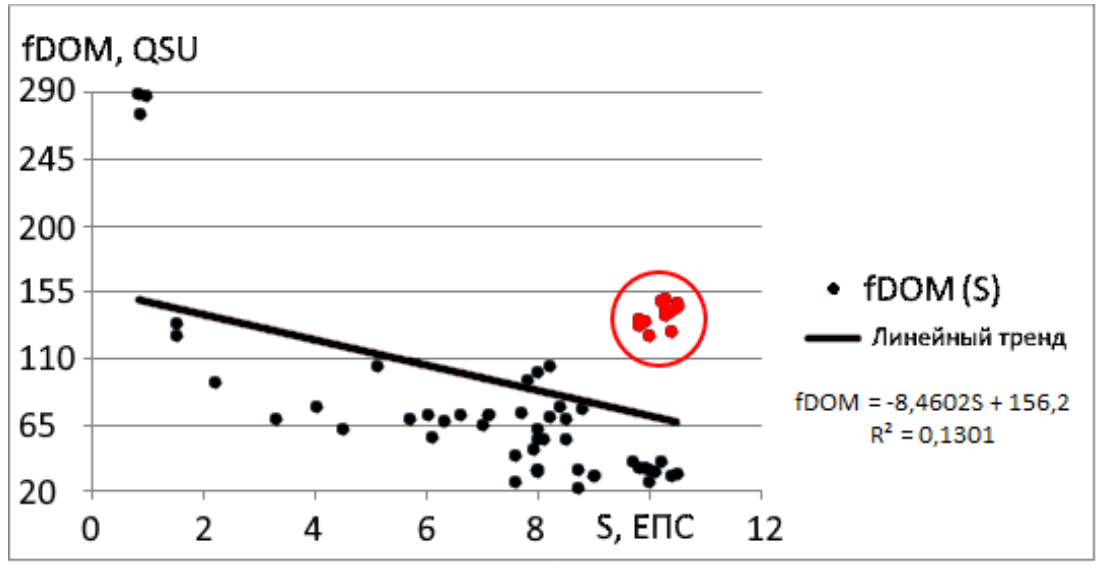

A

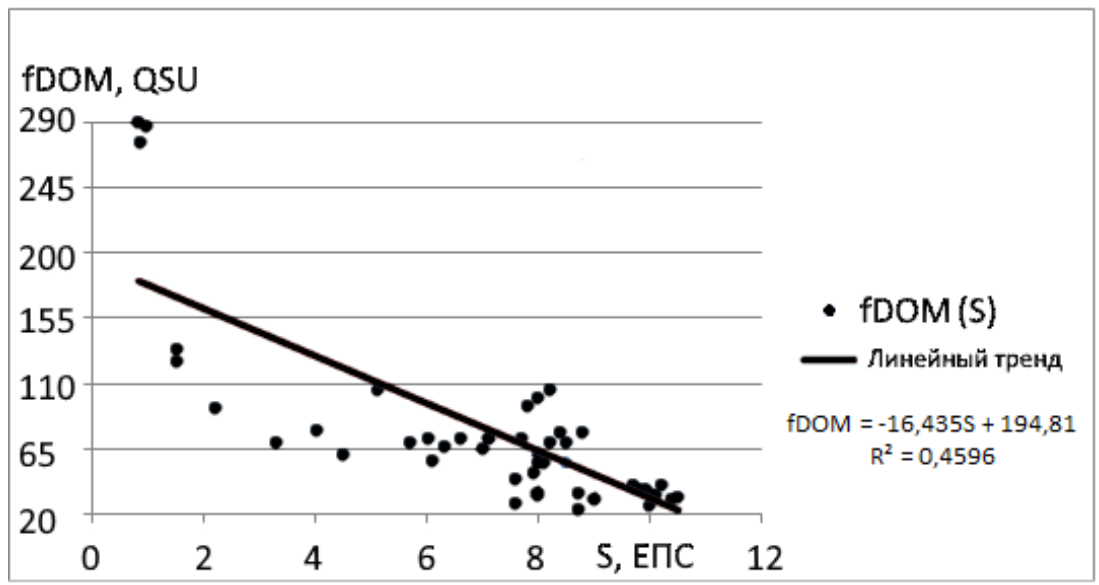

$\mathrm{B}$

Рис. 2. Графики корреляционной зависимости $\mathrm{fDOM}(\mathrm{S})$ для северной части Азовского моря (А — исходная выборка; В — выборка, отфильтрованная от антропогенного fDOM)

На рис. 2B изображён график корреляционной зависимости $\mathrm{fDOM}(\mathrm{S})$, рассчитанный по отфильтрованной в результате исключения «антропогенных» точек остаточной выборке $(\mathrm{N}=50)$, которая соответствует природному полю концентрации fDOM. Данный график иллюстрирует обратную корреляционную связь средней тесноты $(\mathrm{R}=-0,68)$ между исследуемыми величинами для халинной фронтальной зоны у северного берега Азовского моря, которая описывается уравнением регрессии $\mathrm{fDOM}=-16,43 \times \mathrm{S}+194,81$.

Согласно литературным данным [Пугач, Пипко, 2012; Kaiser et al., 2017; Kari et al., 2018; Sasaki et al., 2013; Chaichitehrani, 2012; Hopkins et al., 2013], аналогичные тесные обратные корреляционные зависимости концентрации РОУ и fDOM от солёности свойственны прибрежным акваториям Балтийского и Южно-Китайского морей, северному шельфу Мексиканского залива, шельфовой зоне Атлантического океана в районе устья р. Конго, которые распреснены речным стоком.

В загрязнённом Балтийском море, у берегов Швеции, авторами статьи [Kari et al., 2018] выявлена обратная корреляционная зависимость между солёностью и концентрацией РОУ с коэффициентом $\mathrm{R}=-0,68$ - связь такой же тесноты и знака, что и в анализируемой ситуации в Азовском море (рис. 2А). В прибрежных водах Восточно-Сибирского моря, не подверженных столь мощной антропогенной нагрузке, как Балтийское и Азовское моря, коэффициент корреляции между солёностью и концентрацией РОУ достигает $-0,93 \ldots-0,95$ [Пугач, Пипко, 2012]. 
Литературные данные, а также результат корреляционного анализа, иллюстрируемый рис. 2, свидетельствуют о существенном влиянии антропогенной составляющей в поле исследуемой величины на тесноту корреляционной зависимости $\mathrm{fDOM}(\mathrm{S})$. Тесная обратная корреляционная зависимость fDOM(S) - показатель незначительного присутствия fDOM (POB) антропогенного происхождения в исследуемой акватории. Слабая отрицательная связь, её отсутствие или смена знака - признак наличия растворённой органики антропогенной природы.

На рис. 3 представлены схемы распределения содержания fDOM, рассчитанные на основе средних месячных полей солёности из Атласа [Climatic atlas..., 2006] и уравнения регрессии (рис. 2В). Видно, что в распреснённой акватории с ростом солёности (от 1 до 10 ЕПС) от берега в сторону моря концентрация fDOM уменьшается в диапазоне 300-30 QSU.

Уменьшение содержания РОВ (fDOM) с ростом солёности в распреснённых прибрежных водах связывают с процессом взаимной коагуляциии, наблюдаемой при смешении морской и речной воды, когда ионы солей морской воды адсорбируются на заряженных коллоидных частицах речной воды, в результате чего происходит их коагуляция. По этой причине на дне постепенно скапливается значительное количество ила [Айлер, 1982].

Из уравнения регрессии следует, что на внешней границе области распреснения при $S=10$ ЕПС концентрация fDOM равна 31 QSU. Поэтому в качестве внешней границы распреснённых вод в поле fDOM может быть принята изолиния концентрации этого вещества в 30 QSU.

Мористее границы распреснения терригенная составляющая в поле содержания fDOM, обусловленная речным стоком, резко уменьшается. В центральной, западной и южной частях Азовского моря поле этой величины однородно с концентрацией 20-25 QSU.

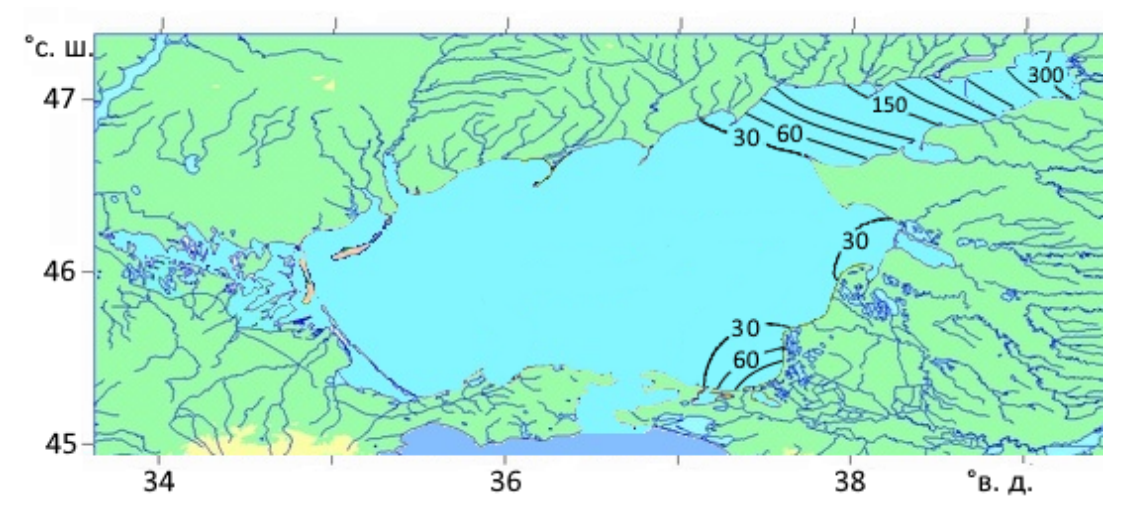

A

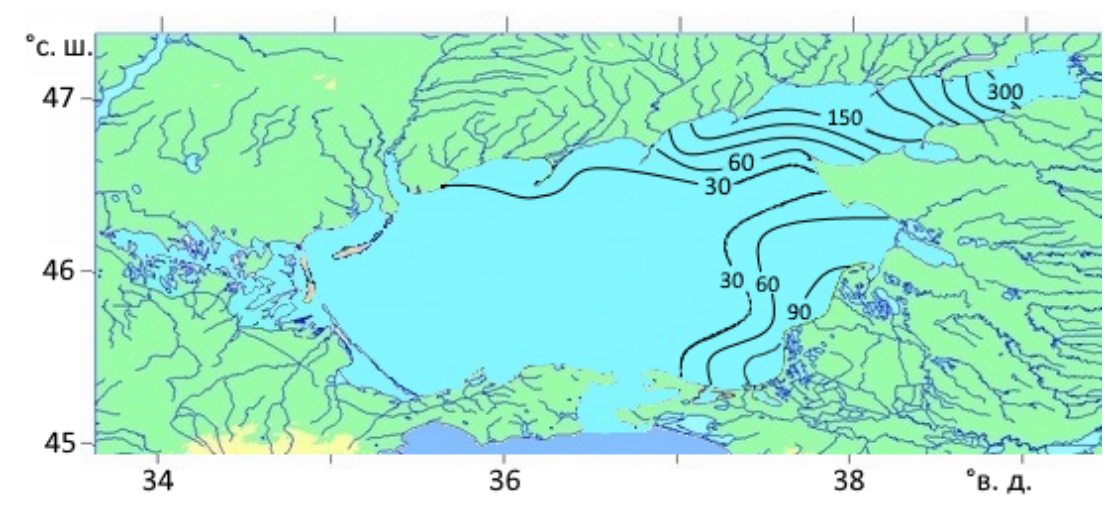

B

Рис. 3. Концентрация fDOM, QSU на поверхности Азовского моря в июне (А) и в марте (B) 
По данным синхронных наблюдений за анализируемыми величинами, накопленными в ходе многочисленных экспедиций МГИ, в водах открытых акваторий Чёрного моря, у берегов Крымского полуострова, при солёности 18,2-18,4 ЕПС концентрация fDOM близка к указанным выше значениям и равна 15-20 QSU.

К югу от границы прибрежной стоковой халинной зоны, расположенной в северной части Азовского моря, до открытых вод Чёрного моря поле содержания fDOM в верхнем слое вод однородно. Это свойство обусловлено существенным уменышением вклада терригенной составляющей в поле концентрации этого вещества.

Площадь прибрежных акваторий у северных и восточных берегов Азовского моря, характеризуемых высоким содержанием fDOM, испытывает существенные сезонные вариации, определяемые сезонным ходом объёма материкового стока.

В летние месяцы года, в межень, при минимальном распреснении прибрежных вод максимум содержания fDOM (30-300 QSU) наблюдается в Таганрогском заливе, куда впадает наиболее полноводная река бассейна Азовского моря - Дон. Другой по значимости локальный максимум содержания fDOM наблюдается на юго-востоке моря, в приустьевом районе второй по водности реки региона - Кубани. Акватория с максимальной концентрацией исследуемого вещества в это время года составляет примерно $15 \%$ от всей площади моря (рис. 3А).

В начале весны, во время паводка, значимые максимумы концентрации fDOM формируются вдоль северного и восточного берегов моря, куда это вещество поступает со стоком менее масштабных по водности рек. Площадь региона с максимальной концентрацией исследуемого вещества во время паводка увеличивается примерно вдвое (рис. $3 \mathrm{~B}$ ).

\section{Выводы}

На основе материалов серии экспедиций, проведенных МГИ и ЮгНИРО в 2002-2015 гг., получено уравнение регрессии, свидетельствующее о наличии обратной корреляционной связи средней тесноты $(\mathrm{R}=-0,68)$ между солёностью и концентрацией fDOM в прибрежных водах северной части Азовского моря. При помощи этого уравнения по известным схемам средней месячной солёности рассчитаны и проанализированы сезонные поля содержания исследуемого вещества для всей прибрежной акватории моря, которая испытывает влияние речного стока.

Установлено, что знак и теснота корреляционной зависимости между рассмотренными величинами характеризуют степень загрязнения морской среды растворённым органическим веществом искусственного происхождения. Тесная обратная корреляционная зависимость $\mathrm{fDOM}(\mathrm{S})$ - показатель незначительного присутствия fDOM антропогенного происхождения в исследуемой акватории. Слабая отрицательная связь, её отсутствие или прямая зависимость признак наличия растворённой органики антропогенной природы.

Показано, что у подверженных распреснению северного и восточного берегов Азовского моря полю исследуемой величины свойственна высокая концентрация fDOM (30-300 QSU), обусловленная терригенной составляющей, вклад которой скачкообразно уменьшается на стоковых фронтах впадающих в море рек. Мористее фронтов в центральной, западной и южной областях Азовского моря поле fDOM отличается однородностью. Концентрация этого вещества здесь примерно такая, как в смежной акватории Чёрного моря, 15-20 QSU.

Летом, в межень, прибрежная акватория с высоким содержанием fDOM составляет примерно $15 \%$ от всей площади моря. Весной, во время паводка, акватория с высоким содержанием fDOM распространяется на всё северное и восточное побережье Азовского моря и увеличивается вдвое. 


\section{Список литературы}

1. Агатова А. И., Лапина Н. М., Торгунова Н. И. Особенности распределения органического вещества в водах Чёрного моря // Система Чёрного моря / Ин-т океанологии им. П. П. Ширшова РАН ; отв. ред. А. П. Лисицын. - Москва : Науч. мир, 2018. - С. 146-170. https://doi.org/10.29006/978-5-91522-473-4.2018.146

2. Айлер $Р$. Химия кремнезёма: растворимость, полимеризация, коллоидные и поверхностные свойства, биохимия. Ч. 1. - Москва : Мир, 1982. - С. 113.

3. Гидрометеорологические условия морей Украины. Т. 1. Азовское море / Ю. П. Ильин [и др.]. Севастополь : [б. и.], 2009. - 400 с.

4. Комплекс гидробиофизический мультипараметрический погружной автономный «КОНДОР» // Hydrooptics Ltd. Development creation research : [каталог оборудования] / Ecodevice. [Sevastopol], cop. 2021. - URL: http://ecodevice.com.ru/ecodevice-catalogue/multiturbidimeterkondor (дата обращения: 26.10.2020).

5. Пугач С. П., Пипко И. И. Динамика растворённого окрашенного органического вещества на шельфе Восточно-Сибирского моря // Доклады академии наук. - 2012. - Т. 447, № 6. C. 671-674.

6. Chaichitehrani $N$. Investigation of colored dissolved organic matter and dissolved organic carbon using combination of ocean color data and numerical model in the Northern Gulf of Mexico : master's theses / Louisiana State University, LSU Digital Commons. - 2012. - URL: https://digitalcommons.lsu.edu/cgi/viewcontent.cgi?article=1248\&context=gradschool_theses (дата обращения: 26.10.2020).

7. Climatic atlas of the Sea of Azov / Eds.: G. Matishov, S. Levitus. - Washington : U. S. Government Printing Office, 2006. - 103 pp. - URL: https://www.nodc.noaa.gov/OC5/AZOV2006/start.html (дата обращения: 26.01.2021).

8. Donázar-Aramendía I., Sánchez-Moyano J. E., García-Asencio I., Miró J. M., Megina C., GarcíaGómez J. C. Impact of dredged-material disposal on soft-bottom communities in a recurrent marine dumping area near to Guadalquivir estuary, Spain // Marine Environmental Research. - 2018. Vol. 139. - P. 64-78. - https://doi.org/10.1016/j.marenvres.2018.05.010

9. Hopkins J., Lucas M., Dufau C., Sutton M., Stum J., Lauret O., Channelliere C. Detection and variability of the Congo River plume from satellite derived sea surface temperature, salinity, ocean color and sea level // Remote Sensing of Environment. - 2013. - Vol. 139. - P. 365-385. https://doi.org/10.1016/j.rse.2013.08.015

10. Kaiser D., Konovalov S., Schulz-Bull D. E., Waniek J. J. Organic matter along longitudinal and vertical gradients in the Black Sea // Deep Sea Research. Part I : Oceanographic Research Papers. - 2017. - Vol. 129. - P. 22-31. - https://doi.org/10.1016/j.dsr.2017.09.006

11. Kari E., Merkouriadi I., Walve J., Leppäranta M., Kratzer S. Development of underice stratification in Himmerfjärden bay, North-Western Baltic proper, and their effect on the phytoplankton spring bloom // Journal of Marine Systems. - 2018. - Vol. 186. - P. 85-95. https://doi.org/10.1016/j.jmarsys.2018.06.004

12. Sasaki H., Gomi Y., Asai T., Shibata M., Kiyomoto Y., Okamura K., Morinaga K., Nishiuchi K., Hasegawa T., Yamada H. Ocean color satellite-derived salinity using colored dissolved organic matter(CDOM) in river-influenced region // Journal of the Japan Society for Marine Surveys and Technology. - 2013. - Vol. 25, iss. 2. - P. 2_13-2_18. - https://doi.org/10.11306/jsmst.25.2_13

13. Shanmugam P., Varunan T., Jaiganesh S. N. N., Sahay A., Chauhan P. Optical assessment of colored dissolved organic matter and its related parameters in dynamic coastal water systems // Estuarine, Coastal and Shelf Science. - 2016. - Vol. 175. - P. 126-145. https://doi.org/10.1016/j.ecss.2016.03.020 
14. Simonini R., Ansaloni I., Cavallini F., Graziosi F., Iotti M., N'Siala G. M., Mauri M., Montanari G., Preti M., Prevedelli D. Effects of long-term dumping of harbor-dredged material on macrozoobenthos at four disposal sites along the Emilia-Romagna coast (Northern Adriatic Sea, Italy) // Marine Pollution Bulletin. - 2005. - Vol. 50, iss. 12. - P. 1595-1605. https://doi.org/10.1016/j.marpolbul.2005.06.031

15. Stronkhorst J., Ariese F., Van Hattum B., Postma J. F., de Kluijver M., Den Besten P. J., Bergman M. J. N., Daan R., Murk A. J., Vethaak A. D. Environmental impact and recovery at two dumping sites for dredged material in the North Sea // Environmental Pollution. - 2003. - Vol. 124, iss. 1. - P. 17-31. - https://doi.org/10.1016/S0269-7491(02)00430-X

16. Van der Wal D., Forster R. M., Rossi F., Hummel H., Ysebaert T., Roose F., Herman P. M. J. Ecological evaluation of an experimental beneficial use scheme for dredged sediment disposal in shallow tidal waters // Marine Pollution Bulletin. - 2011. - Vol. 62, iss. 1. - P. 99-108. https://doi.org/10.1016/j.marpolbul.2010.09.005

\section{FIELD OF COLORED DISSOLVED ORGANIC MATTER IN THE AZOV SEA COASTAL WATERS \\ Lomakin P. D., Zavyalov D. D.}

Marine Hydrophysical Institute, Russian Academy of Sciences, Sevastopol, Russian Federation, e-mail:p_lomakin@mail.ru

On the base of series expeditions, carried out by the Marine Hydrophysical Institute (Sevastopol) and the Southern Research Institute of Marine Fisheries and Oceanography (Kerch) in 2002-2015, regression equation with close inverse relation between salinity and concentration of colored dissolved organic matter in the coastal Azov Sea waters is received. Using this equation on average monthly salinity schemes the seasonal fields of colored dissolved organic matter content are calculated and the first submissions of their structure in the investigated water areas are formed. It is shown that in the northern and eastern shores of the sea the studied field contain a significant component which stipulated by the river runoff. This component is completely transformed on the stock fronts of the rivers flowing into the sea. Seaward of the fronts in the central, western and southern regions of the Azov Sea, the dissolved organic matter field is homogeneous.

Keywords: colored dissolved organic matter, salinity, pollution, Azov Sea.

\section{Сведения об авторах}

Ломакин

Павел

Демьянович

Завьялов

Дмитрий

Дмитриевич доктор географических наук, профессор, ведущий научный сотрудник отдела океанографии, ФГБУН ФИЦ «Морской гидрофизический институт РАН», p_lomakin@mail.ru

младший научный сотрудник отдела океанографии, ФГБУН ФИЦ «Морской гидрофизический институт РАН», evilfence@ya.ru 